\title{
Effects of Repeated Reading and Rhyming Poetry on Reading Fluency
}

\author{
Elisavet Zavala $^{1} \&$ Josh Cuevas $^{1}$
}

${ }^{1,2}$ University of North Georgia, USA

Correspondence: Josh Cuevas, University of North Georgia, USA

Email: jocue24@yahoo.com

doi: 10.23918/ijsses.v6i2p64

\begin{abstract}
This study tested two instructional methods meant to improve elementary students' automaticity, phonemic awareness, oral fluency, and reading comprehension. Twelve $1^{\text {st }}$ grade students received either repeated reading or rhyming poetry instruction. A matched group design was used, and then a single subject analysis was employed to determine if either of the methods was associated with improvements in students' reading achievement, oral reading fluency, and attitudes towards reading. Findings indicated that students who experienced the rhyming poetry intervention tended to show greater improvements in reading comprehension and oral reading fluency, while those exposed to repeated reading showed mixed results. Students from both conditions showed similar improvements in attitude toward reading, though those in the rhyming poetry group showed slightly more improvement in the area. Overall results suggest that both methods may be beneficial to students' reading but that rhyming poetry instruction may have greater potential for students at this level.
\end{abstract}

Keywords: Repeated Reading, Rhyming Poetry, Reading Fluency, Automaticity, Reading Comprehension, Phonemic Awareness

\section{Introduction}

In order for students to be successful in school they need to be fluent readers. Fluent readers are able to read the words in a text as well as comprehend the text. What happens when a student is not able to read the words because he struggles in decoding? As a result of poor decoding this student will also not be able to understand what he read. According to Kuhn, Rasinki, and Zimmerman (2014) fluent readers need to read with appropriate speed, expression, phrasing and comprehension. Reading fluency is a skill that teachers can help struggling readers develop in order for them to become better readers. Reading fluency requires word recognition and comprehension of a text simultaneously. Teaching reading fluency in order to help struggling readers become fluent readers seems to be an effective method.

\section{Reading Fluency}

In order for students to be successful in school as well as in life they need to be fluent readers. Even though this may be the case many students continue to struggle in reading because they are unable to decode. Reading fluency is a skill that good readers should develop to more easily read any type of text (Grabe, 2010). Even though there is no set definition for reading fluency researchers agree that a fluent reader reads with ease and accuracy, as well as with expression, and word recognition (Grabe, 2010; Kuhn et al., 2014; Rasinski, Rupley, Pagie, \& Nichols, 2016). Automatic word recognition means that students do not have to spend time trying to decode the words; instead they can focus on understanding the text. When a reader is unable to automatically read words, it will require more time to complete the task compared to fluent readers (Rasinski et al., 2016). This will place the student behind his peers. Even when students are 
able to learn and use decoding skills, they more than likely focus all of their energy on decoding that they will not read with fluency (Rasinki et al., 2016). A good reader needs to be able to read with automaticity, or with the ability to recognize words instantly and effortlessly (Rasinki, 2014). When a student's focus is on decoding, they are unable to read with automaticity. A lack of automaticity can decrease students' progress to reading for meaning and learning (Rasinki, 2014; Rasinki et al., 2016).

Part of reading instruction is to teach fluency in order to help students become successful readers. Park, Chaparro, Preciado, and Cummings (2015) hypothesized that the earlier foundational skills and reading fluency are mastered the better reading skills outcomes will be at the end of second grade and third grade. They conducted a study with 1,322 students who were followed from kindergarten to third grade. These students received 90 minutes of daily reading instruction. In the spring of each year reading fluency was measured with DIBELS. The data was analyzed using ANOVA analysis, and the results indicated that students' long-term reading outcomes could be positively impacted by influencing the time point at which they reach mastery fluency levels. The findings of this study add evidence to support the importance of reading fluency, especially in the lower grades.

\section{Comprehension}

Reading fluency does not only help students read a text, but it also helps them understand it. Struggling readers will use all their energy on decoding words in the text and will lose focus on the meaning behind the text. Reading fluency is beneficial because once students reach that point, they use minimal cognitive resources to decode; instead they are able to focus their attention on making meaning and understanding the text (Rasinki, 2014). Rasinki et al. (2016) explain that when a reader has mild difficulties in word identification the reader's attention is pulled away from the meaning, causing a decrease in reading rate and requiring the reader to reread in order to understand the text. Kuhn et al. (2014) expand upon this by saying that students who lack fluency in reading look closely at each individual word and as a result are unable to self-monitor or comprehend the text. The reading process requires students to be able to decode or read printed words quickly and accurately, but if students are unable to decode text fluently they will have also have problems understanding the text (Kostewicz et al., 2016). When a student is able to read something with reading expression that shows the author's purpose and meaning, the reader demonstrates that he has a grasp of the meaning of the text (Rasinki, 2014). When a student is focusing so much on decoding the words, the oral reading of the text is broken and expressionless. When finished with the text, the student will not be able to summarize the text or answer questions about the text, since the focus was on only decoding and not on both reading and comprehension.

There has been research conducted to answer different questions about reading fluency and comprehension in order to improve reading achievement. Hausheer, Hansen, and Doumas (2011) conducted a study to examine the effectiveness of a remedial reading program designed to improve reading fluency and comprehension in elementary school students. Even though the focus of this study was the effectiveness of the remedial program, the study showed that students who participated in the reading program had an increase in scores for both reading fluency and reading comprehension. Another study conducted by Yildiz and Çetinkaya (2017), sought to find the relationship between good readers' attention, reading speed, word recognition and reading comprehension. The study was conducted in a public school with 132 fourth grade students' data of reading fluency; word recognition and comprehension were collected for three weeks. A 
multiple regression analysis conducted. The researchers concluded that attention in good readers, with adequate grade level reading skills, is associated with reading speed, prosody, reading comprehension and word recognition. These findings illustrate the relationship between reading fluency and reading comprehension.

There was a study conducted by Patton, Crosby, Houchins, and Jolivette (2010) that had a different conclusion about reading fluency and comprehension. The purpose of the study was to investigate the impact of a supplemental fluency-based reading program, Great Leaps Reading Program (GLR) with and without a comprehension strategy. Fifty-nine students were randomly assigned to one of two groups; control-group only received instruction with the GLR program while the experimental group received instruction with the GLR program and comprehension questions. This study concluded that an implementation of a comprehension strategy hinders student's word and text reading skills, in contrast to the other studies mentioned above. According to Patton et al., a reason the comprehension strategy hindered fluency could be based on the age level of the participants. It might be that the students did not have the appropriate level of cognitive development needed to comprehend the stories. The results of the GLR program-only group indicated it had a positive impact on students reading fluency. These findings suggest that text chosen for studies involving reading fluency and comprehension needs to be age level and developmentally appropriate.

\section{Repeated Reading}

There are many approaches to help improve reading fluency, but the focus of all approaches is to help students become fluent readers who are able to recognize words automatically, read at a good pace, and with read with expression (Grabe, 2010; Kostweicz et al., 2016; Kuhn et al., 2014; Rasinki, 2014; Rasinki et al., 2016). In order for students to develop word recognition they must frequently be exposed to words and word patterns to create that automacity (Rasinki, 2014). The repeated exposure of the words and word patterns allows students to store the information in their memory to use for other texts. Students cannot be expected to learn a word or word pattern after only one day. Grabe (2010) explains this by saying that in order to create fluent readers they must have plenty of practice with words and word patterns. This approach is called repeated reading where the focus is to directly improve students' decoding fluency (Kostewicz et al., 2016).

Repeated reading seems to be an effective intervention for the instruction of reading fluency. There are several studies that suggest that repeated reading is effective in stimulating reading gains and improving reading speed and reading accuracy. A study conducted by van Gorp, Segers and Verhoeven (2014) examined the direct transfer and retention effects of a repeated reading intervention on single consonantvowel-consonant words in kindergarteners with partial letter knowledge. Twenty-six kindergarteners participated in a computer-based intervention. A voice-over character guided children in the computer; a word was visible to students and disappeared after they read the word. Students were placed in one of two conditions: either the short feedback condition or the extensive feedback condition. The results of the study showed an increase in reading speed and accuracy with no differences in the two feedback conditions. The results of the study indicate that a repeated reading intervention in kindergarten can be an effective method to improve reading speed and reading accuracy. 
A similar study was conducted by Gellert (2014) where 99 third grade students participated, resulting in data suggesting that children's gains in reading fluency during meaning focused repeated reading contributes to long-term reading development. Hawkins, Marsicano, Schmitt, McCallum and Musti-Rao (2015) also conducted a study to compare the effects of two reading fluency interventions, adult-meditated repeated reading and listening-while-reading, on oral reading fluency. It consisted of 4 male fourth graders. The repeated reading intervention included immediate adult feedback and the listening-while-reading intervention used an MP3 as the listening device. Fluency data indicated that for three of the four students both interventions led to similar Oral Reading Fluency levels, but the listening-while-reading intervention led to more rapid learning than repeated reading. All of these studies suggest that repeated reading is an effective strategy to teach reading fluency.

Rasinki (1990) also conducted a study that compared the effectiveness of repeated reading and listeningwhile-reading on promoting reading fluency. His study consisted of twenty third-grade students from different elementary schools in the Southern United States. Subjects were paired according to reading ability. The same assessment tool, running records, was used for the pretest and posttest. Two 100-word passages at a $4^{\text {th }}$-grade level were used with both treatments. All participants received both treatments, repeated reading and listening-while-reading. Each treatment consisted of a cycle that lasted 4 days. On the first cycle student 1 of the pair would repeatedly read the passage, either independently or with teacher support while student 2 would listen to student 1 read and silently read along. On the next cycle the students were reversed. Contrary to the study that Hawkins et al. (2015) conducted where they found that the listening-while-reading intervention led to more rapid learning than repeated reading, in Rasinki's (1990) study the results show that both the repeated reading and the listening-while-reading treatments were effective in improving reading fluency; neither treatment was better than the other.

The study that Musti-Rao, Hawkins and Barkley (2009) conducted also focused on repeated reading. The purpose of the study was to determine the effects of peer-mediated repeated reading on oral reading fluency. The participants were 12 African American fourth-grade students who were considered to be performing below grade level. The study focused on the students' oral reading fluency, focusing on the words read per minute. The students were administered fourth-grade level passages from the DIBELS oral reading fluency. Students were paired and received training on the peer-mediated repeated reading procedures. One student from the pair had the role of the listener, and another student had the role of the reader. At the beginning of each session the students took turns reading a passage for 10 minutes, correcting each other as needed. After the 10 minutes, the students were asked to read the passage independently for 1 minute. The results of the study indicate that peer-mediated repeated reading improved students' oral reading rate.

Lo, Cooke, and Starling (2011) also conducted a study that focused on effects of a repeated reading intervention on oral reading fluency. The study was conducted at a Title 1 school in the urban district in the southeast region of the United States. Three second-grade students participated in the study. The intervention sessions consisted of unison reading with an adult trainer and repeatedly reading a passage for four or five times with error corrections. The results of the study showed that repeated reading improved fluency for the three participants. All of these studies suggest that to some extent repeated reading is an effective strategy to teach reading fluency. 
Swain, Leader-Jassen and Conley (2017) conducted a case study where they examined the effectiveness of three fluency interventions: repeated reading, audio listening passage preview and teacher modeled listening passage preview. A fifth grade student received the interventions that consisted of seven weeks. At the end of the intervention the researchers found data indicating that each intervention increased oral fluency but listening passage preview resulted in the greatest fluency growth. This case study demonstrates how repeated reading was effective in increasing oral fluency, but it is not the only way to help improve it.

\section{Phonemic and Phonological Awareness}

Not only is repeated exposure necessary to increase reading fluency but also instruction that allows for the gradual release of responsibility. To help with reading fluency the teacher must model how reading sounds like. The teacher uses expression to help the listeners understand the text and hear how a fluent reader sounds (Rasinki, 2014). Next, the teacher uses assisted reading where the teacher, or peer, reads the same text with the student. Since the reader has guidance, he is able to hear someone else read with expression and does not have to focus on decoding words. After guided practice students are ready to begin repeated or independent practice. This can be in the form of simply letting students read text on his or her self; it could be the same text or a different text (Kuhn et al., 2014; Rasinki, 2014; Rasinki et al., 2016). This instruction in the form of gradual release of responsibility provides students with the needed support to become fluent readers.

Rasinki et al. (2016) suggest combining the instruction of phonics and fluency as a teaching model. The type of text they suggest to use in this type of reading fluency instruction is rhyming poetry. The goal is to teach students common orthographic patterns that they can apply to familiar texts as well as to unfamiliar texts. This approach in using rhyming poetry to teach fluency is a more engaging way to keep students focused on the pattern. First, the word patterns are learned in isolation, but as the days progress students are required to read the word patterns in context. This allows students the opportunity to apply what they have learned. The last step is for students to create their own poems with the pattern. On the last step the teacher has released all responsibility, and it is the students' turn to show that they know the pattern, meaning that if they see the pattern in a new text, they will be able to automatically read it.

There does not seem to be experimental research that has focused on the effectiveness of using rhyming poetry as a type of instruction, but there are other studies that have focused on phonological and phonemic awareness. In one study, O'Rourke, Olshtroon, and O'Halloran (2016) agree on the view that struggling readers need texts that allow them to apply the letter sounds correspondence and decoding skills they are taught as well as texts that emphasize reading for meaning and syntactic and semantic cues to allow readers to cross-check and self-regulate. The first goal of the study was to help struggling readers progress through a systematic phonics program. Goal two was to provide daily opportunities in guided oral reading with an on-level text. The Toe-by-Toe phonics program was used daily with 24 , eight-year-old elementary school students. The results of the study show that a systematic phonics program, that focuses first on teaching letter sounds and then blending these sounds together to compose whole words results in reading improvements for struggling readers.

Another study that focused on phonics sought to determine if phonics knowledge influences students' growth in fluent reading. The study by Eldredge (2005) explored a causal relationship between phonics 
knowledge and word recognition and a causal relationship between word recognition and fluency. The study findings suggest that phonics knowledge does contribute to word recognition growth. The finding of the study also indicates that word recognition growth has a casual impact on reading fluency and that phonics and word recognition appear to be a precursor for reading fluency and comprehension. The findings from both studies suggest that phonics instruction seems to be an important aspect to teach reading fluency.

Martens, Werder, Hier and Koenig (2013) focused their study on phonemic awareness instead of phonics instruction. The purpose of their study was to examine the effects of fluency training in phoneme blending and reading gains. The study also focused on oral reading accuracy and fluency as well as phonemic awareness, specifically concentrating on vowel teams. Martens et al. had a small sample of 3, secondgrade students, all three performing on the frustration level of the DIBELS assessment. Students were trained and assessed on vowel teams. The results suggest that training students to blend words in isolation with modeling and feedback followed by practice and reinforcement for generalizing the skills to untrained words on a list may be an effective teaching method to promote generalized oral reading competence. All three students showed generalized increases from trained to untrained words in reading fluency and in words containing the targeted vowels teams in target and generalization passages. The study of Martens et al. (2013) is more aligned to the rhyming poetry instruction Rasinki et al. (2016) suggest in order to teach reading fluency.

In the study that Ashby, Dix, Bontrager, Dey and Archer (2013) conducted they also focused on phonemic awareness. The longitudinal study was conducted to investigate the relationship between phonemic awareness and text reading fluency. The study investigated the relationship by measuring eye movements during matching tasks and silent reading. Ten children from central Michigan with an average age of 7.7 participated in the study. Eye movements were assessed in the fall of second grade and in the fall of third grade in 30-45 minute sessions. Each session consisted of an approach called Eyespy where the eye movements of the children were monitored while they performed linguistic awareness tasks and read silently for comprehension. Eyespy would measure the online processing difficulty during the picture matching tasks. The tasks consisted of phonemic awareness, receptive spelling, silent reading and oral reading. The children's eye movement was measured. The findings of the study suggest that poor phonemic processing contributes to poor silent reading fluency after second grade.

Studies show that reading fluency has a positive impact on students reading achievement. When a student is able to automatically read a word, time is not spent on trying to decode the word, which allows the student to fluidly read a passage. There are no interruptions in the reading, so the student has more time to think about the text. Readers with automatic word recognition also read faster than their peers who are less automatic (Rasinki, 2014). Even though research shows that reading fluency is beneficial for students it is not always the primary focus for teachers, instead they focus on decoding, resulting, as Kuhn et al. (2014) explain, in numerous of students struggling in their fluency development. If these students are the same students who also struggle in decoding, then direct and intensive fluency instruction may be needed.

\section{Research Questions}

Many studies have examined the importance of reading fluency to help students become efficient readers. The focus of many of these studies has been using repeated reading as the form of instruction to improve 
reading fluency. Not many studies have focused on the use of rhyming poetry as a combination of instruction to teach phonics and fluency. According to Rasinki et al. (2016) the goal in using rhyming poetry is to teach students common orthographic patterns that they can apply to familiar texts as well as to unfamiliar texts. This approach in using rhyming poetry to teach fluency is a more engaging way to keep students focused on the pattern. This study seeks to determine answers to the following research questions:

1. Does using rhyming poetry intervention have an effect on reading fluency and grade level reading achievement?

2. Does using repeated reading intervention have an effect on reading fluency and grade level reading achievement?

3. How do students' attitudes towards reading change after been exposed to one of the two interventions?

\section{Method}

\subsection{Contextual Factors}

The study was conducted in a county in northeast Georgia. The district was chosen due to geographic accessibility. The demographics of the district represent a rural population. The largest ethnic groups in the district are $78.0 \%$ White, followed by $13.5 \%$ Hispanic and 3.8\% African American (Georgia Demographics). The median household income for the 2015-year was $\$ 40,907$. However, $17.8 \%$ of the residents live in poverty.

The demographics of the city in which the study was conducted differ somewhat from those of the district. The ethnic groups represented in the city are 52.9\% White, followed by $35.1 \%$ Hispanic and $6.8 \%$ African American (Georgia Demographics). The median household income in 2015 was $\$ 29,956$. In the city $39.3 \%$ of the residents live in poverty.

The elementary school where the study was conducted was made up of 663 students, grades ranging from pre-k- $5^{\text {th }}$ grade, and 53 full time teachers. Fifty two percent of the student population was identified as Hispanic. A large portion of the students participated in the National School Lunch Program; 75.4\% received free lunch and 9.2\% received reduced lunch (public-schools.startclass.com). The study was conducted in a first grade classroom during Reading. The student/teacher ratio was 14:1, with 2 White students, 3 African Americans, 1 Asian and 8 Hispanic students with a breakdown of 6 boys and 8 girls. One of the 14 students qualified for Special Education services and 6 students qualified for ESOL services. Two students from the classroom did not participate in the study due to an excess of absences. Thus, only 12 students participated in the study and were grouped based on ability grouping in order to ensure that the two groups had similar reading levels and were placed in either the reading group or the rhyming poetry group; each group consisted of 6 students.

\section{Materials and Measures}

Prior to the start of the study all students were screened to assess their oral reading fluency (ORF), Literacy Classification, and Students Growth Percentile (SGP) by using the STAR Early Literacy assessment. The 
classroom teacher administered the STAR assessment. The STAR Early Literacy assessment uses multimedia and computer-adaptive technology and requires minimum teacher assistance while students take the assessment. Multiple-choice questions continually adjust in difficulty based on a student's previous response. The assessment allows educators to identify a student's command of phonemic awareness, phonics, general readiness, graphophonemic knowledge, comprehension, structural analysis, and vocabulary in approximately 10 minutes (School Renaissance Inst, 2001). This same assessment was used at the end of the study to determine the students' reading growth.

In order to determine if there was a change in attitude towards reading after the implementation of the intervention students completed a survey before the study began and at the end of the study. The instrument used was the Elementary Reading Attitude Survey designed by McKenna and Kear (1990). The teacher read the scenario and then the students circled the Garfield picture that best fit their attitudes to that situation. Attitudes describe either recreational reading or academic reading. Each item was assigned 1, 2, 3 or 4 points with 4 indicating the happiest, represented by the leftmost Garfield. See Appendix A for survey. The Cronbach's alpha coefficient total for this survey for first grade was .87 (McKenna \& Kear, 1990).

The same materials were used for both interventions. A poem that followed the phonics pattern for the week was projected on the board for students. The same poem was also provided to students as a hardcopy for the times when students were required to read independently or when they were required to read with a partner. Therefore, there were a total of four poems in the course of the study. The poems followed the following phonics patterns: -ick, -ay, -all and -ing. See Appendix B for an example of the poem. An assessment consisting of ten words was given at the end of each week. See Appendix $C$ for an example of the assessment. The ten words followed the phonics pattern for the week and were used as a comparison tool between the two interventions.

\section{Procedures}

Matched group design was used to place participants in ability groups based on their reading levels. The matched groups were formed based on the pretest scaled scores from the STAR test. The students were divided into the groups based on their scaled score. The two students with the highest scores were each placed in rhyming poetry intervention or repeated reading intervention. The students continued to be divided into the two groups based on their scores until both groups had similar representation. The study was completed across 4 weeks with intervention sessions of 10-15 minutes, 2 times per week. All students continued to receive the traditional daily 60 -minute reading instruction. In both conditions the same teacher-made short reading poem passages were used for instruction. The short reading poem passages included a word family pattern. In the repeated reading condition students were not be explicitly made aware of the pattern while in the rhyming poetry condition different activities were completed in order to explore the pattern.

The short reading passage included words that followed a different word family pattern each week. Therefore, a new word family pattern was introduced each week and assessed at the end of the week it was introduced. The weekly assessment included 10 words that students were required to read correctly 
without the need to sound out each individual sound. The word family patterns that were used were; -ing, -ell, -ick and -ay.

Repeated Reading. On day one the teacher presented the students with a reading poem passage and instructed the students to read along with her. The teacher projected the poem passage on the board, and as she was reading it out loud she would point to each word so that the students could easily follow along. After reading the passage with the teacher, students were assigned to read the passage with a partner. There were no assigned partners. Students choose whom they wanted to work with, and they sat together and read the poem; each partnership received a hardcopy of the poem. During this time the teacher observed students and corrected reading errors if needed. On day two participants read the same reading passage independently. Each student received his or her own copy of the poem, allowing for easier access for reading of the poem. This means that in total students were exposed to the passage on three occasions. On Fridays, students were given an assessment that required them to orally read a list of words that contained the learned word family pattern. This process continued for the remainder of the 4 weeks; passage read aloud with teacher, passage read with partner, passage read independently, and assessment on words read correctly that followed the word family pattern.

On the last week of the study participants were given the STAR Early Literacy assessment as the posttest. Data from the assessment prior to conducting the study were compared to the data on the latest STAR assessment, to examine the change in the ORF, Literacy Classification and SGP. Rhyming Poetry. Using the rhyming poetry model of instruction from Rasinki et al. (2016), on the first day the teacher wrote a word family pattern on an anchor chart demonstrating the spelling and the sound. See Appendix D for an Anchor Chart. Participants were then asked to brainstorm more words that followed the same pattern, which the teacher wrote on the anchor chart. Participants were given the short reading passage that followed the word family pattern. The teacher and the students read the passage out loud. While reading the passage the teacher guided students into noticing that the passage was composed of words that were spelled and pronounced similarly. This brought attention to the students about the rhyming words in the passage. Students had prior knowledge of what it meant for words to rhyme and how authors sometimes use rhyming words to write poems. This knowledge helped the students and the teacher explore the passage to determine if the passage was a poem. After determining that the passage was a poem, the teacher asked students to find the words in the poem that rhymed with the words they wrote on the anchor chart. The following rhyme from Rasinki et al. (2016) is an example of a similar reading passage that students were exposed to in order to practice and learn the -ot word family: "Peas porridge hot, Peas porridge cold, Peas porridge in the pot, Five days old". On day two the teacher reviewed the word family and students independently read the passage. Following the same assessment procedures as the repeated reading condition, on Fridays after the two sessions students were given an assessment of a list of words that followed the word family pattern from the last two sessions.

On the last week of the study participants in this intervention were also given the STAR Early Literacy assessment as the post-test. Data from the assessment prior to conducting the study was compared to the data on the latest STAR assessment looking at the change in the ORF, Literacy Classification and SGP. 


\section{Results}

\subsection{Automatic Word Recognition}

This study was conducted in order to determine the effects that rhyming poetry and repeated reading interventions had on reading fluency and grade level reading achievement. At the end of each session all students were given a list of ten words that followed the word family pattern that was taught that week. The students read each word and the teacher took note of each word that was read correctly. Figure 1 shows the mean score of words that students read correctly at the end of each intervention session. In the repeated reading intervention, the line graph stayed relatively flat showing that there was not much growth in the mean number of words that students were able to read at the end of the sessions. The line graph for the rhyming poetry intervention shows that there was an increase in growth of the mean number of words that students in the rhyming intervention read correctly. The results on Figure 1 show how the students in the rhyming poetry intervention made more gains at the end of the sessions.

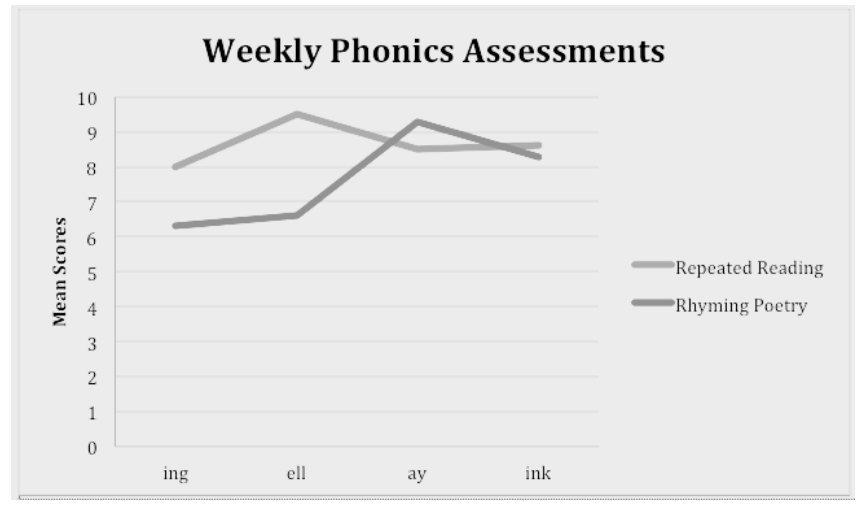

Figure 1: Weekly Phonics Assessments

\subsection{Effects of Repeated Reading Intervention}

In order to answer the first research question, the Early Literacy STAR test was used as the pre-test instrument and the post-test instrument in order to help determine the effect that repeated reading had on students' reading achievement and reading fluency. Figure 2 shows the individual results of the scaled scores for the students in the repeated reading intervention group. Three out of six students in this group had an increase in their scaled score at the end of the intervention, and three students had a decrease in their score at the end of the intervention. Student 7 had an increase of 31 points on the scaled score while Student 8 and Student 11 had an increase of more than 70 points on their scaled scores. Figure 3 shows the results of the oral reading fluency scores that the students received in the pre-test and post-test of the STAR Early Literacy test for the repeated reading group. In the repeated reading intervention group three students had an increase in their oral reading fluency scores while three students had a decrease in their scaled scores. The same three students, Student 7, Student 8, and Student 11, were the ones who had an increase in both the scaled score and their oral reading fluency score. Student 9, Student 10 and student $12 \mathrm{had}$ a decrease in both their scaled score and their oral reading fluency score. 


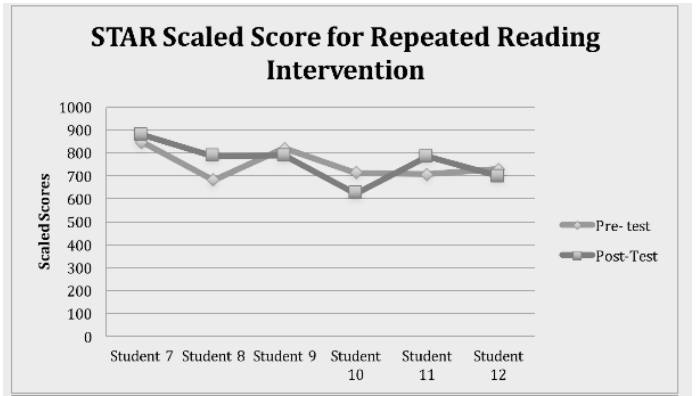

Figure 2: STAR Scaled Score for RR

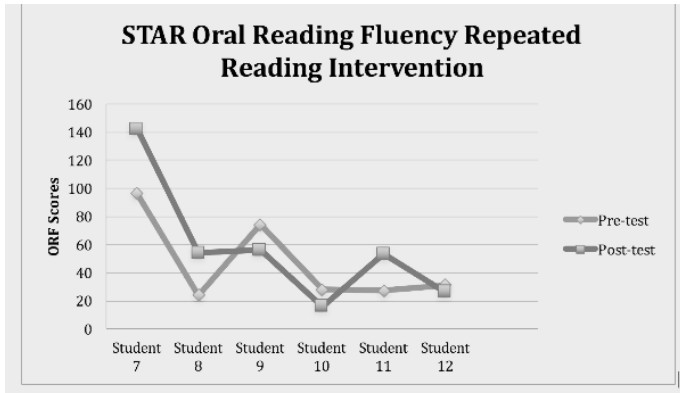

Figure 3: STAR Scaled Score for RP

\subsection{Effects of Rhyming Poetry Intervention}

In order to answer the second research question, the Early Literacy STAR test was also used as the pretest instrument and the post-test instrument in order to help determine the effect that rhyming poetry had on students reading achievement and reading fluency. Figure 4 shows the individual results of the scaled score for the students in the rhyming poetry intervention. In the rhyming poetry intervention group, five out of six students increased their scaled score and only one decreased in his or her score. The graph shows how Student 2, Student 5, and Student 6 increased their scaled score by more than 70 points from the pretest to the post-test, while Student 1 only increased the scaled score by 4 points and Student 4 only increased 1 point on the post-test. Figure 5 demonstrates the results of the pre-test and post-test for each students' oral reading fluency scores. The results show that four students increased their oral reading fluency on the STAR test, one student received the same score, and one student decreased in his or her score. The student who had a decrease in the scaled score was the same student who had a decrease in the oral reading fluency score. The student who only had a one-point increase in the scaled score was also the student who received the same score on the pre-test and post-test for the oral reading fluency section of the STAR test.

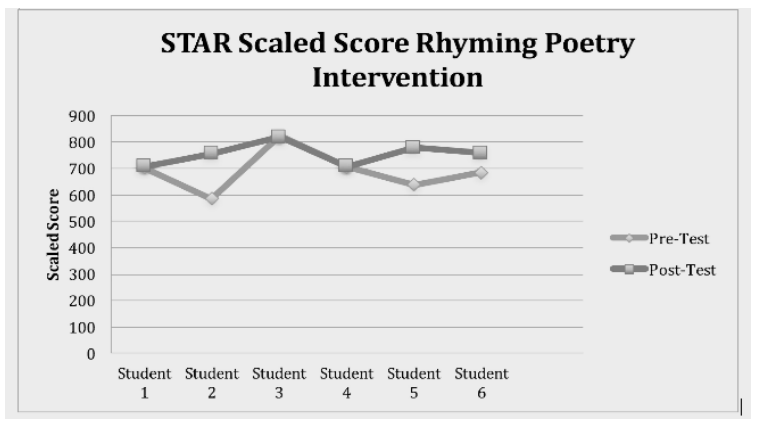

Figure 4: STAR Scaled Scores for RP

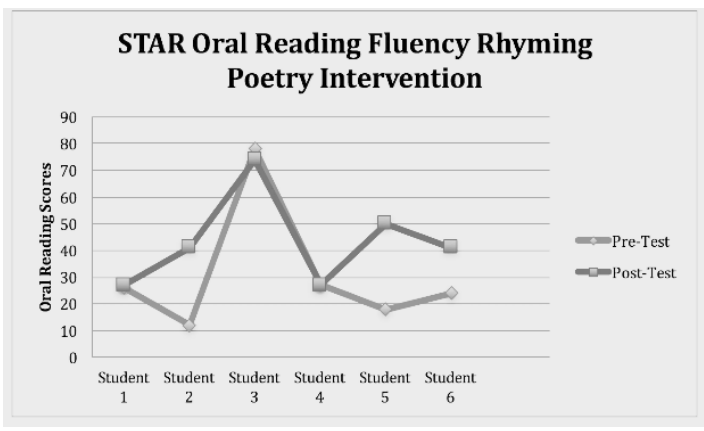

Figure 5: STAR ORF scores for RP

\subsection{Comparison of Both Interventions}

The following figures focused on comparing the two interventions in order to determine which intervention had the greatest impact on student reading fluency and grade level reading achievement. Figure 6 compares the mean of the scaled scores of the pre-test and post-test of both interventions. In the 
rhyming poetry intervention, the mean scaled score for the pre-test was 690.6 while the mean scaled score for the repeated reading intervention was 750 . On the pre-test, the students in the repeated reading intervention had a higher mean scaled score than the rhyming poetry intervention. On the post-test, the rhyming poetry intervention group had a mean scaled score of 754.6 while the repeated reading intervention group had a mean scaled score of 761.1. Figure 7 compares the mean scores of the students' oral reading fluency results from the STAR test in both the pre-test and the post-test. In the rhyming poetry intervention, the mean score for the pre-test was a score of 30 while the post-test mean was a 43.3. In the repeated reading intervention, the mean score for the pre-test was 46.6 and the mean for the post-test was a score of 57.8 .

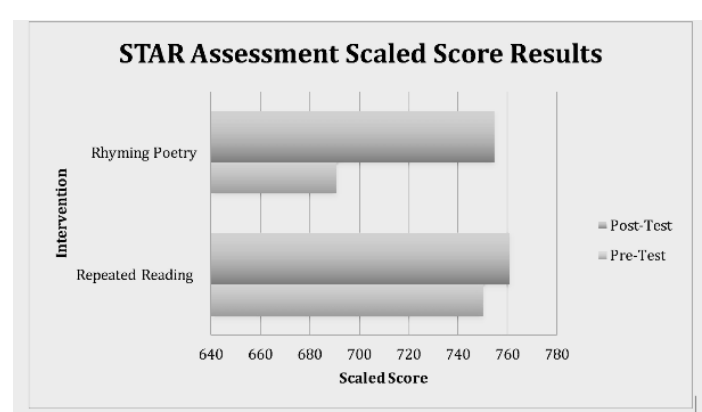

Figure 6. STAR Assessment Scaled Score Results

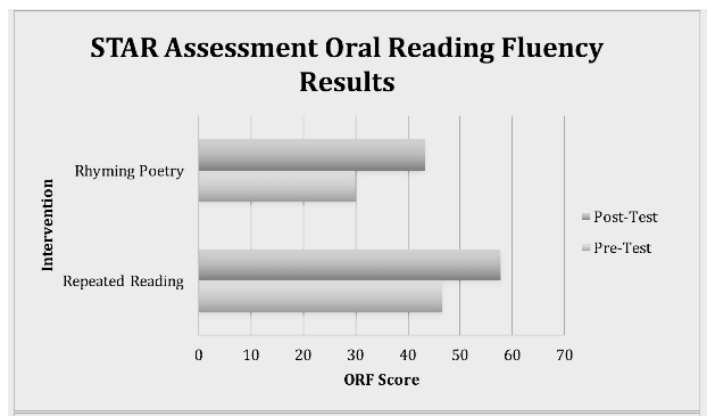

Figure 7. STAR Assessment ORF Results

\subsection{Attitude Towards Reading Survey}

The pre-test and post-test survey results are shown in Figure 8 and Figure 9. After each student completed the survey, they were given a percentile rank based on their overall score. Based on the percentile rank in the rhyming poetry intervention, five students had a positive change in attitude towards reading while one student had a negative change in attitude towards reading. In the repeated reading intervention four students had a positive change in attitude towards reading and two students had a negative change in attitude towards reading.

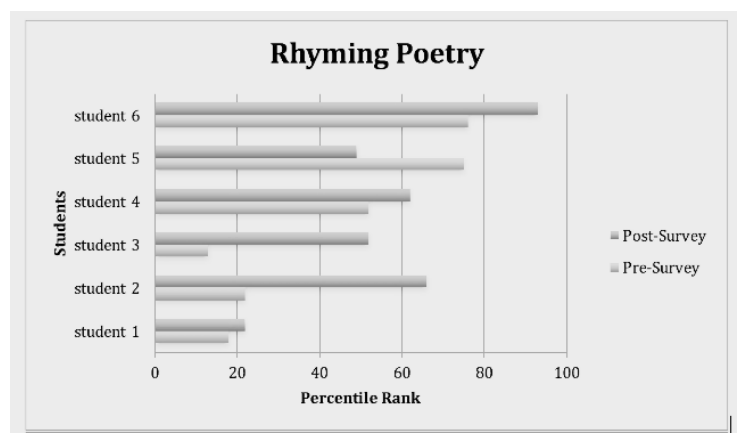

Figure 8. Survey Results for RP Intervention

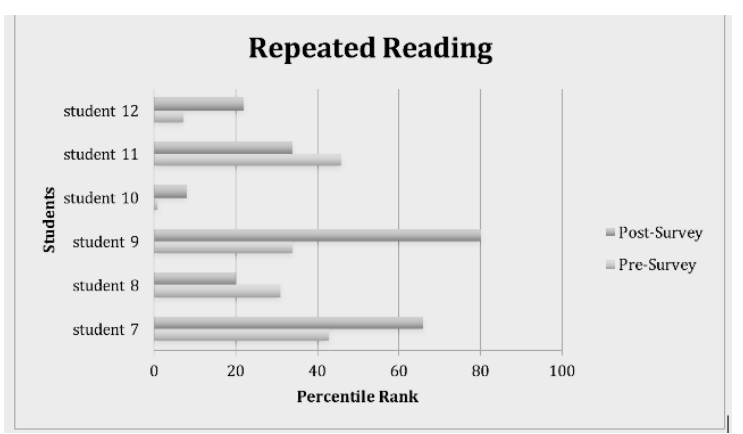

Figure 9. Survey Results for RR Intervention 


\section{Discussion}

This study sought to determine the effects that two interventions had on reading fluency and grade level reading achievement. The results for the repeated reading intervention show that repeated reading did seem to have had a positive effect on some students' reading fluency and grade level reading achievement, but the overall data shows that there was not a uniformly positive effect. By looking at Figure 2 and Figure 3 it shows that three out of the six students in the repeated reading group had an increase in their scaled scores as well as an increase in their oral reading fluency scores. These results indicate that even though repeated reading did not impact all students to the same degree, some students did make gains with the implementation of this intervention. These results align with the research results in the study that Rasinki (1990) conducted while comparing the effectiveness of repeated reading with another intervention. Similar to the results of this study, Rasinki concluded that the repeated reading intervention was effective in improving reading fluency. Another study conducted by Musti, Hawkins, and Barkley (2009) focused on the effects of peer-mediated repeated reading on oral reading fluency. Just like Rasinki (1990), the data from this study indicated that peer-mediated repeated reading improved students' oral reading rate.

The results for the rhyming poetry intervention also showed that a rhyming poetry intervention seemed to have a positive effect on most of the students' reading fluency and grade level reading achievement. Figure 4 shows that five students in the rhyming poetry intervention group had an increase in their scaled score, and only one had a decrease in the scaled score. Figure 5 shows the results for the oral reading fluency section of the assessment, and it demonstrates how four students increased in score, one received the same score, and one student decreased in his or her score. The results indicate that more than half of the students in the rhyming poetry group had an increase in both their oral reading fluency scores and in their scaled scores. Since the rhyming poetry intervention centered on the usage of phonics with instruction that focused on using word families in order to improve reading fluency, this study has a similar conclusion to the study that Eldredge (2005) conducted. At the end of his study the data he collected suggests that there seems to be a causal relationship between phonics knowledge and reading fluency. Ashby, Bontrager, Dey and Archer (2013) conducted a longitudinal study to investigate the relationship between phonemic awareness and text reading fluency. The findings of the study suggest that poor phonemic processing contributes to poor silent reading fluency, and thus improved phonemic awareness should accompany improvements in fluency which did seem to be the case in the current study.

The first two research questions that the study sought to answer focused on the effect that repeated reading and rhyming poetry have on reading fluency. Based on the weekly word recognition assessments and the results from the early literacy test reflected by students' scaled scores and reading fluency scores, the rhyming poetry intervention had a greater effect on the increase of students' reading fluency. When the pre-test and post-test scaled scores for each intervention are compared, the results show that the rhyming poetry intervention had a greater impact on student growth. In the rhyming poetry intervention, there was an increase of 64 points in the mean of the students' scaled scores, while in the repeated reading intervention there was only an increase of 11.1 points in the students' mean scaled scores. Referring back to the research questions and based on the results of the students' STAR scaled scores, it suggests that rhyming poetry seems to have had a greater effect on reading fluency than repeated reading in this study. 
The difference in the score of the oral reading fluency between both interventions was not substantial, but the results continue to indicate that the rhyming poetry intervention seems to have had a greater effect on the students' reading fluency. By looking at the difference between the pre-test and post-test of each intervention, the rhyming poetry intervention resulted in a 13.3 increase in the mean of oral reading fluency score compared to the repeated reading intervention which had an 11.2 increase in the group mean. Overall the results indicate that both interventions may have had an effect on reading fluency and grade level reading achievement, but rhyming poetry had a greater effect than repeated reading.

The purpose of the study was also to determine if the attitudes of the students changed after being exposed to one of the interventions. The results of the change in the percentile rank from the pre-surveys and postsurveys that the students completed indicate that both interventions had a positive effect on the students' attitudes towards reading. However, the rhyming poetry intervention seemed to have the greatest positive effect on students' change in attitude towards reading after being exposed to the intervention.

\subsection{Limitations of the Study and Directions for Future Research}

There were some limitations throughout the course of this study that need to be taken into account for possible future research. Since the duration of the study was only four weeks and was composed of such a small sample size, the results cannot be generalized. Due to the small sample size, groups for both interventions were not equal. Matched groups were used to try and create similar groups, but the groups in this study were not equally composed. Even though the STAR test scaled scores were used to place students in matched groups, the groups were composed of students with very differing reading levels. Another limitation was that since the population was chosen due to convenience, the groups were relatively homogenous in their racial and demographic make-up.

Based on the results from the small sample size group, the rhyming poetry intervention seems to have a positive effect on reading fluency. For future researchers, it is suggested that a larger sample size be used in order to allow enough data to be collected to try to find statistically significant gains. If a larger sample size is used it will also help to lead to groups that are more heterogeneous in racial and demographic backgrounds. Another design that is suggested for future studies is a longer duration of the interventions.

\section{Conclusion}

The findings in this study and the literature suggest that even though repeated reading did have some effect on some students' reading fluency and reading achievement, the rhyming poetry intervention was the more effective intervention that classroom teachers may be able to use to help increase reading fluency. The rhyming poetry intervention may have a greater effect on reading fluency than a repeated reading intervention. Since reading fluency is an integral skill that students should develop in order to be successful readers, a classroom teacher can use rhyming poetry as part of her instruction, and based on the results of this study, it gives some reason to expect the students would show an increase in their reading fluency.

\section{References}

Ashby, J., Dix, H., Bontrager, M., Dey, R., \& Archer, A. (2013). Phonemic awareness contributes to text reading fluency: Evidence from eye movements. School Psychology Review, 42(2), 157-170. 
Eldredge, J. L. (2005). Foundations of fluency: An exploration. Reading Psychology, 26(2), 161-181. doi:10.1080/02702710590930519

Gellert, A. S. (2014). Does repeated reading predict reading development over time? A study of children from grade 3 to 4. Scandinavian Journal of Psychology, 55(4), 303-310. doi:10.1111/sjop.12132

Georgia Demographics. (2015) [Data File] Retrieved from https://www.georgiademographics.com/habersham-county-demographics

Georgia Demographics. (2015) [Data File] Retrieved from https://www.georgiademographics.com/cornelia-demographics

Grabe, W. (2010). Fluency in reading-Thirty-five years later. Reading in a Foreign Language, 22(1), 7183.

Hausheer, R., Hansen, A., \& Doumas, D. M. (2011). Improving reading fluency and comprehension among elementary students: Evaluation of a school remedial reading program. Journal of School Counseling, 9(9).

Hawkins, R. O., Marsicano, R., Schmitt, A. J., McCallum, E., \& Musti-Rao, S. (2015). Comparing the efficiency of repeated reading and listening-while-reading to improve fluency and comprehension. Education and Treatment of Children, 38(1), 49-70.

Kostewicz, D. E., Kubina, R. M., Selfridge, K. A., \& Gallagher, D. L. (2016). A review of fixed fluency criteria in repeated reading studies. Reading Improvement, 53(1), 23-33.

Kuhn, M., Rasinki, T., \& Zimmerman, B. (2014). Integrated fluency instruction: Three approaches for working with struggling readers. International Electronic Journal of Elementary Education, 7(1), 71-82.

Lo, Y., Cooke, N. L., \& Starling, A. P. (2011). Using a repeated reading program to improve generalization of oral reading fluency. Education and Treatment of Children, 34(1), 115-140.

Martens, B. K., Werder, C. S., Hier, B. O., \& Koenig, E. A. (2013). Fluency training in phoneme blending: A preliminary study of generalized effects. Journal of Behavioral Education, 22(1), 16-36.

McKenna, M. C., \& Kear, D. J. (1990). Measuring attitude toward reading: A new tool for teachers. Reading Teacher, 43(9), 626-639.

Musti-Rao, S., Hawkins, R. O., \& Barkley, E. A. (2009). Effects of repeated readings on the oral reading fluency of urban fourth-grade students: Implications for practice. Preventing School Failure, 54(1), 12-23.

O'Rourke, D., Olshtroon, A., \& O'Halloran, C. (2016). The limerick reading initiative: A reading intervention targeted at struggling readers in primary school. Support for Learning, 31(2), 148-163.

Park, Y., Chaparro, E. A., Preciado, J., \& Cummings, K. D. (2015). Is earlier better? Mastery of reading fluency in early schooling. Early Education \& Development, 26(8), 1187-1209. doi:10.1080/10409289.2015.101585

Patton, B., Crosby, S., Houchins, D., \& Jolivette, K. (2010). The comparative effect of fluency instruction with and without a comprehension strategy for elementary school students. International Journal of Special Education, 25(2), 100-112.

Rasinski, T. V. (1990). Effects of repeated reading and listening-while-reading on reading fluency. Journal of Educational Research, 83(3).

Rasinki, T. V. (2014). Fluency matters. International Electronic Journal of Elementary Education, 7(1), 3-12.

Rasinski, T. V., Rupley, W. H., Pagie, D. D., \& Nichols, W. D. (2016). Alternative text types to improve reading fluency for competent to struggling readers. International Journal of Instruction, 9(1), 163-178.

School Renaissance Inst., I. W. (2001). The Development of STAR Early Literacy. Report. 
Start Class. (2017). [Data File] Retrieved from http://public-schools.startclass.com/1/24689/CorneliaElementary-School

Swain, K. D., Leader-Janssen, E. M., \& Conley, P. (2017). Effects of repeated reading and listening passage preview on oral reading fluency. Reading Improvement, 54(3), 105-111.

van Gorp, K., Segers, E., \& Verhoeven, L. (2014). Repeated reading intervention effects in kindergartners with partial letter knowledge. International Journal of Disability, Development \& Education, 61(3), 225-239. doi:10.1080/1034912X.2014.932572

Yildiz, M., \& Çetinkaya, E. (2017). The relationship between good readers' attention, reading fluency and reading comprehension. Universal Journal of Educational Research, 5(3), 366-371. 


\section{Appendix A}

McKenna and Kear Elementary Reading Attitudes Survey (1990)

\section{ELEMENTARY READING ATTITUDE SURVEY}

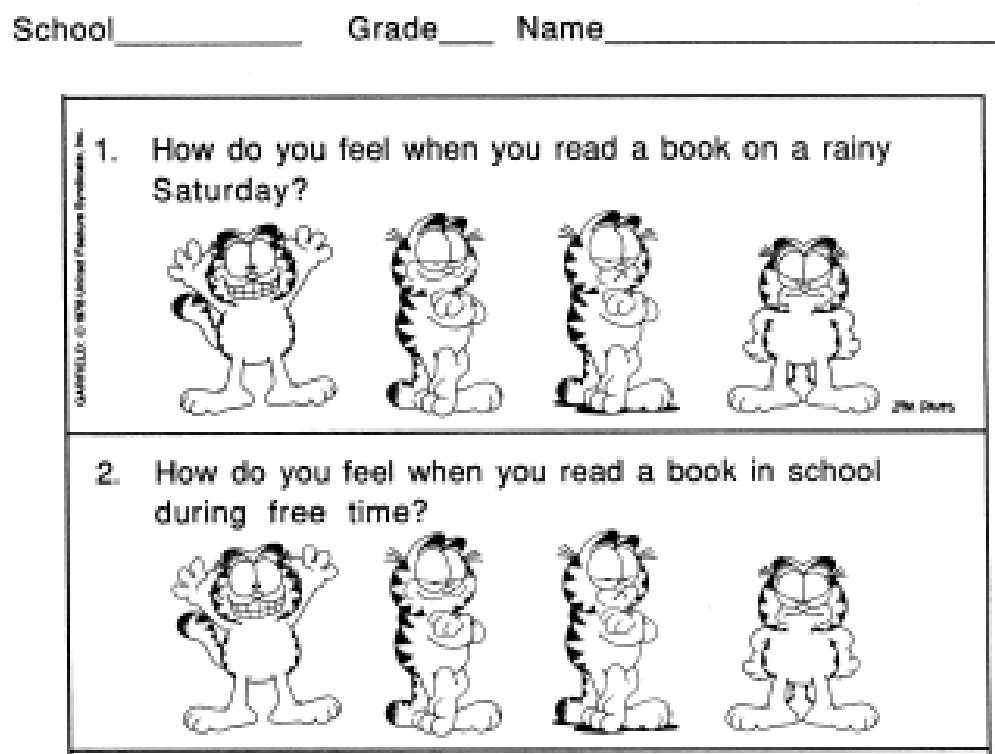

3. How do you feel about reading for fun at home?
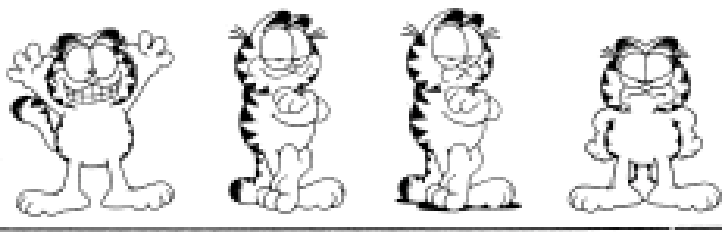

4. How do you feel about getting a book for a present?
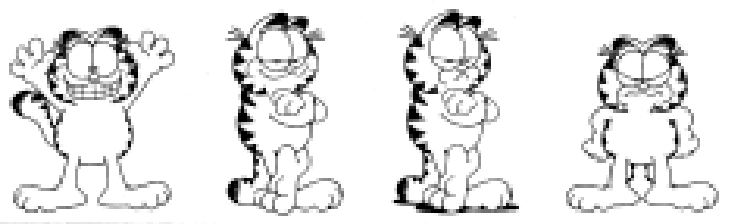
5. How do you feel about spending free time reading?
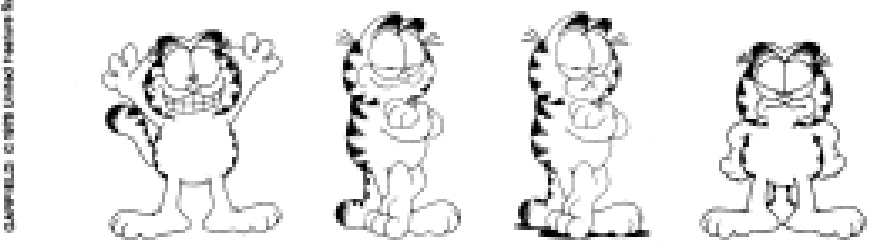

6. How do you feel about starting a new book?
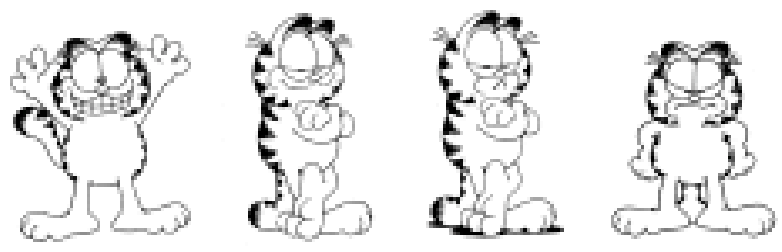

7. How do you feel about reading during summer vacation?
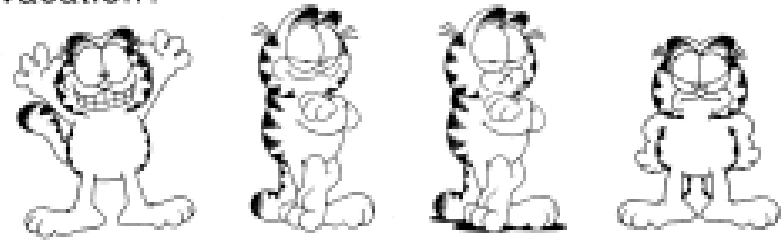

8. How do you feel about reading instead of playing?
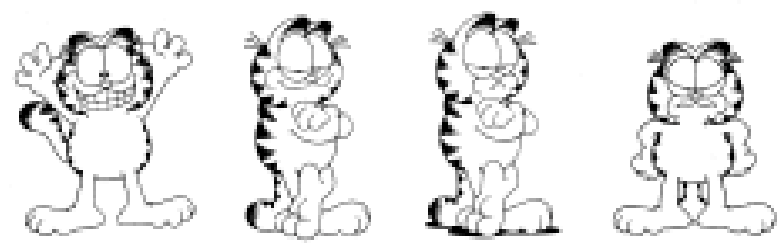
f. How do you feel about going to a bookstore?

$$
\text { ? }
$$
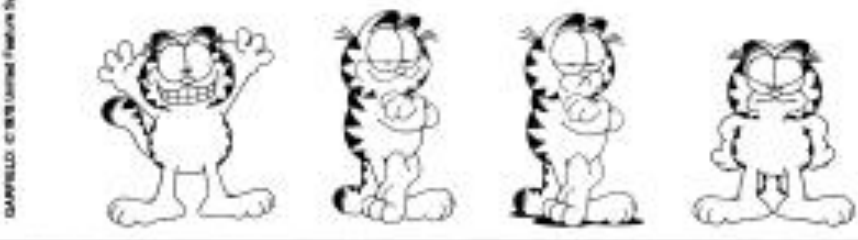

10. How do you feel about reading different kinds of books?
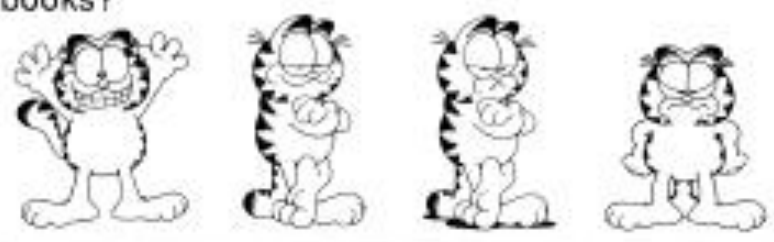

11. How do you feel when the teacher asks you questions about what you read?
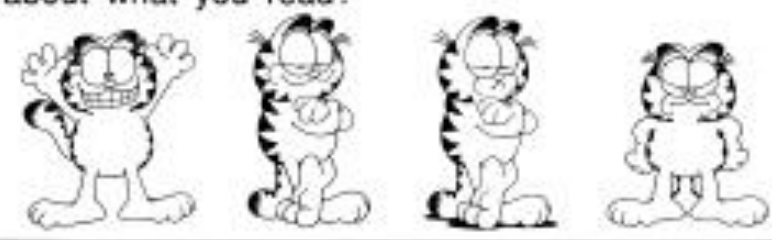

12. How do you feel about doing reading workbook pages and worksheets?
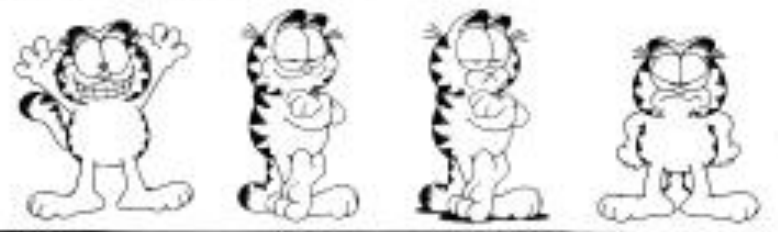

May 1990 
13. How do you feel about reading in school?
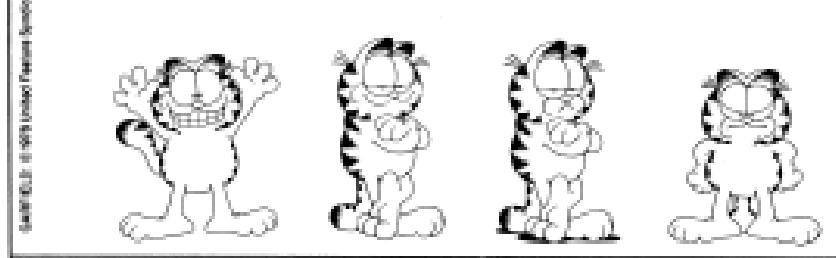

14. How do you feel about reading your school books?
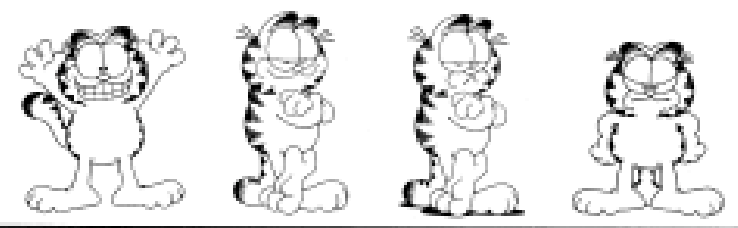

15. How do you feel about learning from a book?
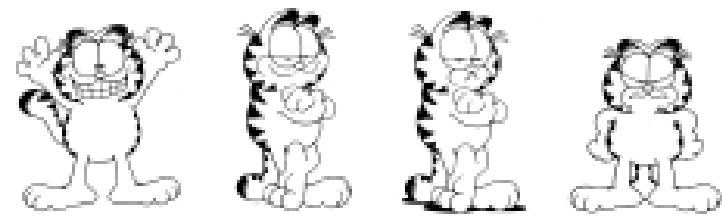

16. How do you feel when it's time for reading class?
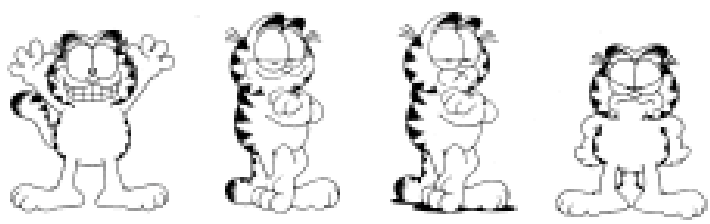

Measuringt attitude toward readine

6.33 


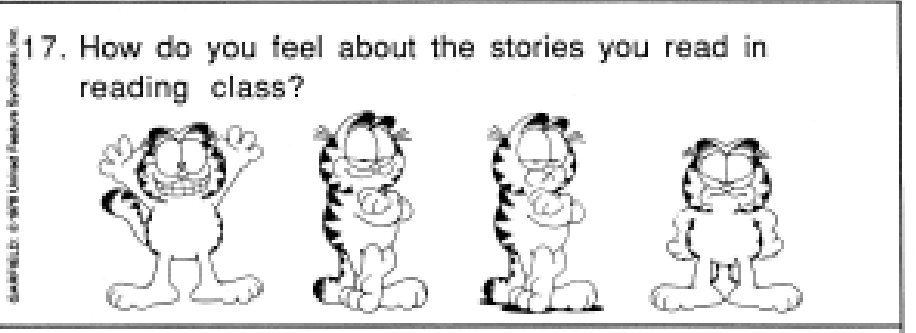

18. How do you feel when you read out loud in class?
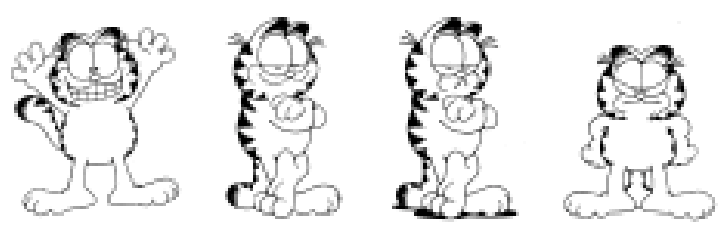

19. How do you feel about using a dictionary?
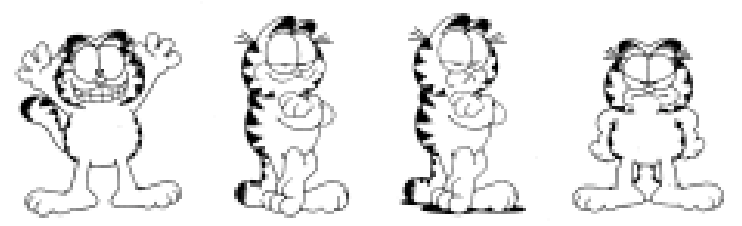

20. How do you feel about taking a reading test?
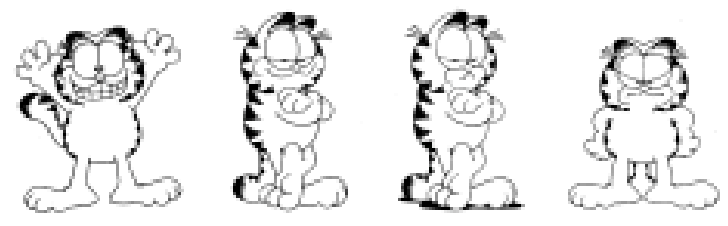
International Journal of Social Sciences \& Educational Studies ISSN 2520-0968 (Online), ISSN 2409-1294 (Print), December 2019, Vol.6, No.2

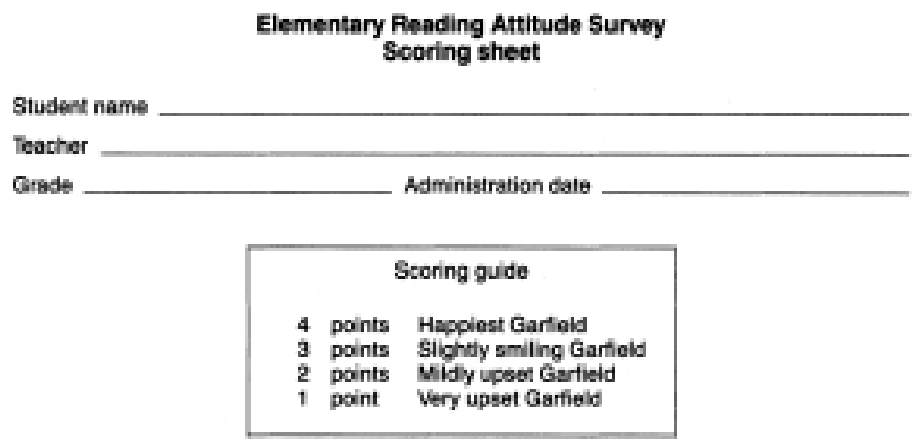

Recreational reading

Acedamic reading

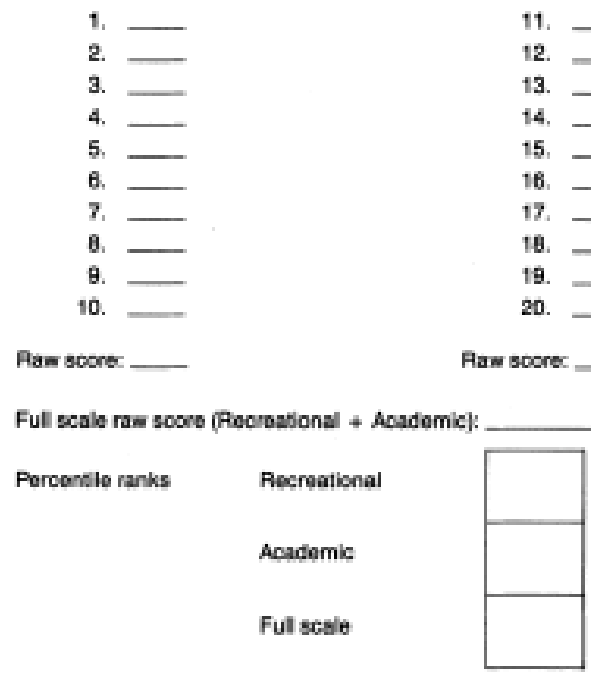

Messurind attitude toward reading $\quad 635$ 
Appendix B

Poem Example

\section{The Well \\ Bob lives in the dell. In his \\ yard, he has a well. On the \\ well, there is a bell. The bell \\ fell in the well. Bob wants \\ to yell! He runs and tells \\ Nell that the bell fell in the}

well.

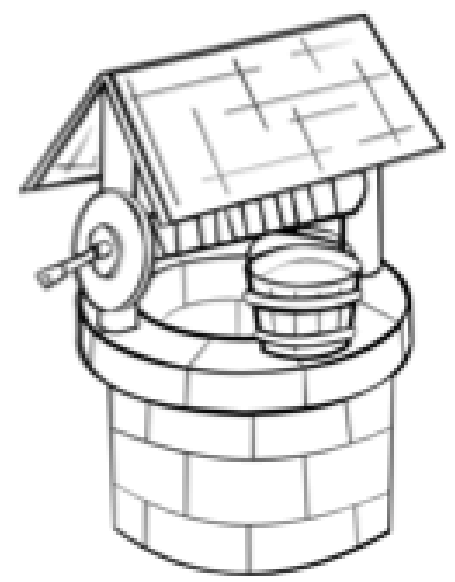


Appendix C

Ten Word Assessment Example

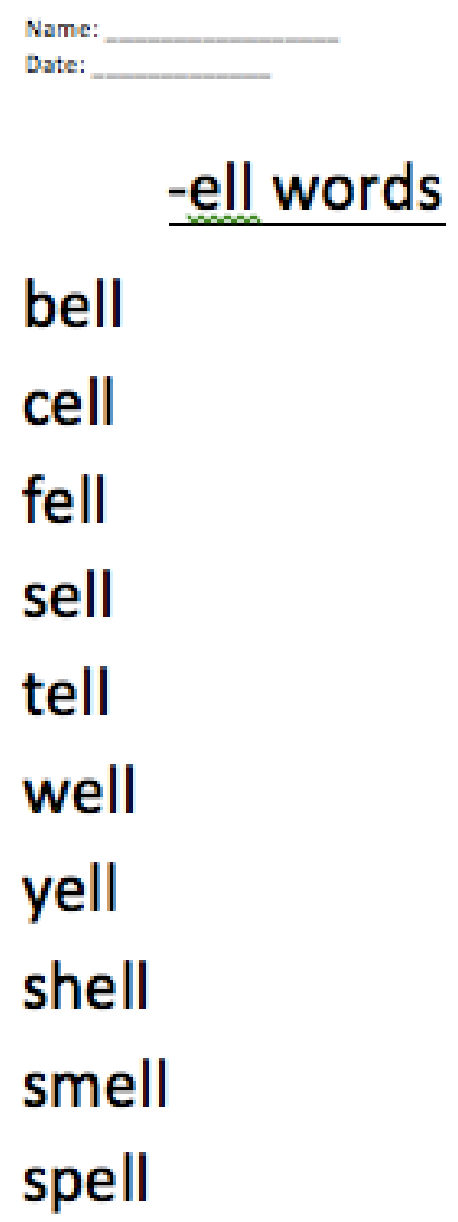


International Journal of Social Sciences \& Educational Studies ISSN 2520-0968 (Online), ISSN 2409-1294 (Print), December 2019, Vol.6, No.2

Appendix D

Word Families Anchor Chart Example
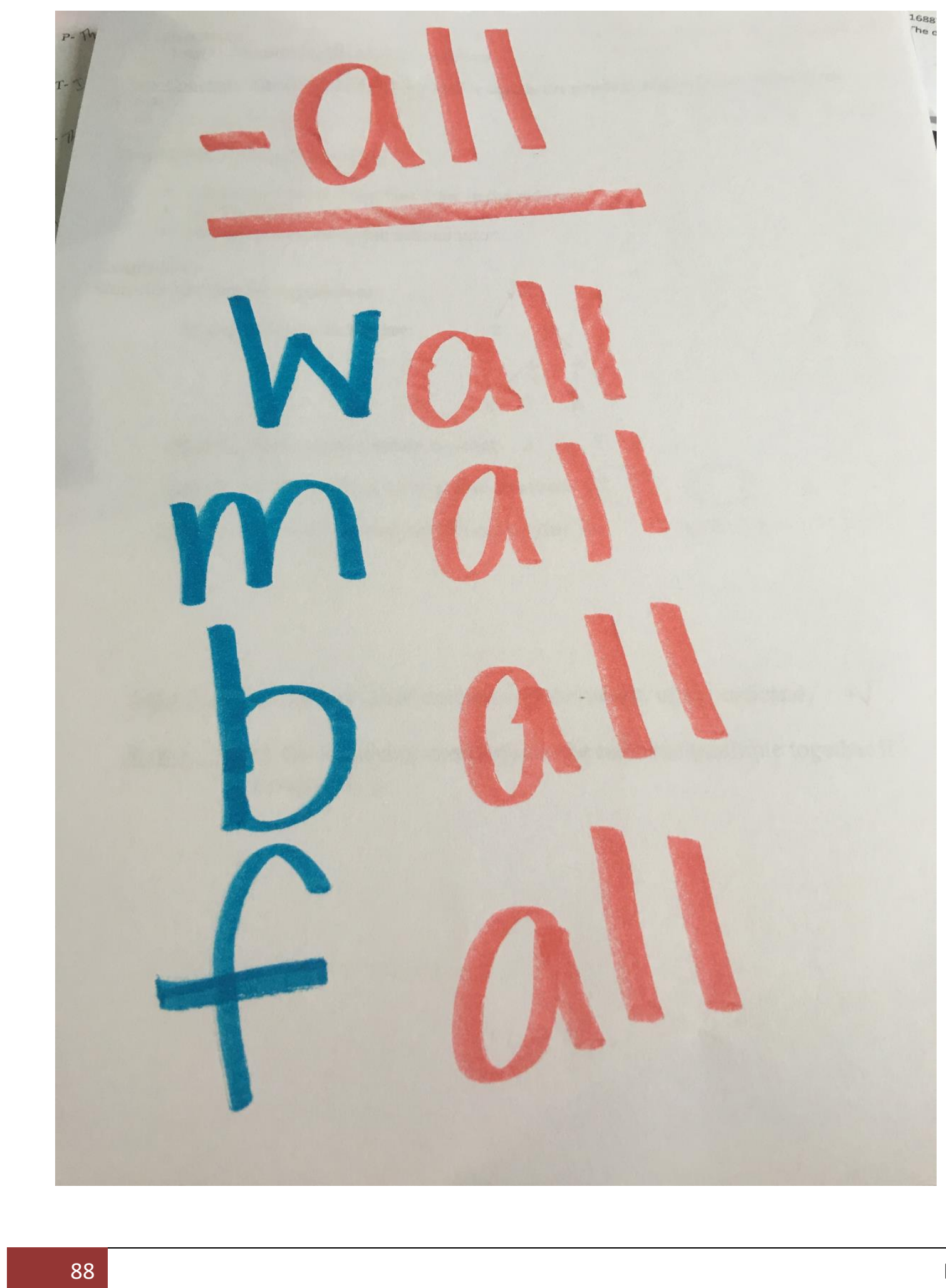

IJSSES 